\title{
Augmented fluoroscopy guided transbronchial pulmonary microwave ablation using a steerable sheath
}

\author{
Mario Ghosn ${ }^{1}$, Ahmed S. Elsakka ${ }^{1}$, Fourat Ridouani ${ }^{1}$, Raphael Doustaly ${ }^{2}$, Louie Mingione ${ }^{3}$, \\ Kevin Royalty ${ }^{3}$, Etay Ziv ${ }^{1}$, Erica Alexander ${ }^{1}$, Aaron Maxwell ${ }^{4}$, Sebastien Monette ${ }^{5}$, Hyun S. Kim ${ }^{6}$, \\ Robert F. Short ${ }^{7}$, Alda Lui Tam ${ }^{8}$, Robert D. Suh ${ }^{9}$, Stephen B. Solomon ${ }^{1}$
}

${ }^{1}$ Interventional Radiology Service, Memorial Sloan Kettering Cancer Center, New York, NY, USA; ${ }^{2}$ GE Healthcare, Buc, France; ${ }^{3}$ NeuWave Medical, Inc., Madison, WI, USA; ${ }^{4}$ The Warren Alpert Medical School of Brown University, Providence, RI, USA; ${ }^{5}$ Laboratory of Comparative Pathology, Memorial Sloan Kettering Cancer Center, The Rockefeller University, Weill Cornell Medicine, New York, NY, USA; ${ }^{6}$ Division of Vascular and Interventional Radiology, Department of Diagnostic Radiology and Nuclear Imaging, Marlene and Stewart Greenbaum Comprehensive Cancer Center, University of Maryland School of Medicine, Baltimore, MD, USA; ${ }^{7}$ Interventional Radiology, Therapeutic and Diagnostic Imaging, Dayton VA Medical Center, Boonshoft College of Medicine, Wright State University, Dayton, OH, USA; ${ }^{8}$ Department of Interventional Radiology, MD Anderson Cancer Center, Houston, TX, USA; ${ }^{9}$ Department of Radiological Sciences, David Geffen School of Medicine, University of California, Los Angeles, CA, USA

Contributions: (I) Conception and design: M Ghosn, F Ridouani, SB Solomon; (II) Administrative support: M Ghosn, R Doustaly, SB Solomon; (III) Provision of study materials or patients: M Ghosn, AS Elsakka, R Doustaly, L Mingione, K Royalty, S Monette, SB Solomon; (IV) Collection and assembly of data: M Ghosn, AS Elsakka, S Monette, SB Solomon; (V) Data analysis and interpretation: M Ghosn, AS Elsakka, S Monette, SB Solomon. (VI) Manuscript writing: All authors. (VII) Final approval of manuscript: All authors.

Correspondence to: Stephen B. Solomon, MD. Chief, Interventional Radiology Service, Enid A. Haupt Chair in Clinical Investigation, Interventional Radiology Service, Memorial Sloan Kettering Cancer Center, 1275 York Avenue, Howard 118, New York, NY 10065, USA.

Email: solomons@mskcc.org.

Background: Transbronchial microwave ablation (MWA) is a promising novel therapy. Despite advances in bronchoscopy and virtual navigation, real time image guidance of probe delivery is lacking, and distal maneuverability is limited. Cone-beam computed tomography (CBCT) based augmented fluoroscopy guidance using steerable sheaths may help overcome these shortcomings. The aim of this study was to evaluate feasibility and accuracy of augmented fluoroscopy guided transbronchial MWA with a steerable sheath and without a bronchoscope.

Methods: In this prospective study, procedures were performed under general anesthesia. Extra-bronchial lung synthetic targets were placed percutaneously. Target and airways extracted from CBCT, with planned bronchial parking point close to the target were overlaid on live fluoroscopy. Endobronchial navigation was solely performed under augmented fluoroscopy guidance. A $6.5 \mathrm{Fr}$ steerable sheath was parked in the bronchus per plan, and a flexible MWA probe was inserted coaxially then advanced through the bronchus wall towards the target. Final in-target position was confirmed by CBCT. Only one ablation of $100 \mathrm{~W}-5 \mathrm{~min}$ was performed per target. Animals were euthanized and pathology analysis of the lungs was performed.

Results: Eighteen targets with a median largest diameter of $9 \mathrm{~mm}$ (interquartile range, $7-11 \mathrm{~mm}$ ) were ablated in 9 pigs. Median needle-target center distance was $2 \mathrm{~mm}$ (interquartile range, $0-4 \mathrm{~mm}$ ), and was higher for lower/middle than for upper lobes $[0 \mathrm{~mm}$ (interquartile range, $0-4 \mathrm{~mm}$ ) vs. $4 \mathrm{~mm}$ (interquartile range, 3-8 mm), $\mathrm{P}=0.04]$. No severe complications or pneumothorax occurred. Two cases of rib fractures in the ablation zone resolved after medical treatment. Median longest axis of the ablation zone on post-ablation computed tomography was $38 \mathrm{~mm}$ (interquartile range, $30-40 \mathrm{~mm}$ ). Histology showed coagulation necrosis of ablated tissue.

Conclusions: Transbronchial MWA under augmented fluoroscopy guidance using a steerable sheath is feasible and accurate. 
Keywords: Ablation techniques; augmented fluoroscopy; cone-beam computed tomography (CBCT); lung neoplasms; steerable sheath

Submitted Oct 28, 2021. Accepted for publication Jan 14, 2022.

doi: $10.21037 /$ tlcr-21-864

View this article at: https://dx.doi.org/10.21037/tlcr-21-864

\section{Introduction}

Bronchoscopic delivery of microwave energy through the airways using a flexible probe, proposed in 2013 by Ferguson et al. (1), aims to decrease complications related to percutaneous transpleural probe placement, namely pneumothorax $(2)$. Pre-clinical studies $(3,4)$ have demonstrated feasibility and early trials demonstrate encouraging results in humans (5-8). Despite technical advances, such as virtual navigation with electromagnetic navigation bronchoscopy (ENB) (9), robotic bronchoscopy (10), ultrathin bronchoscopy and radial endobronchial ultrasound, transbronchial microwave ablation (MWA) faces two major limitations. Guidance wise, simultaneous visualization of probe delivery and accurate assessment of its position in the target are lacking. Indeed, although this is possible with radial endobronchial ultrasound, most virtual navigation bronchoscopy techniques rely on preprocedural computed tomography (CT) imaging and are thus subject to "CT to body divergence" that decreases navigation accuracy $(11,12)$. Device wise, the bronchoscopic approach is associated with limited stability and flexibility when targeting peripheral lung nodules, despite improvements with robotic bronchoscopy $(10,13)$. These drawbacks become particularly relevant in interventional oncology, where accurate probe placement in the tumor and ability to contemporaneously visualize the ablation zone are key for technical success and local tumor control (14).

Fluoroscopy and cone-beam computed tomography (CBCT) may help overcome these limitations $(15,16)$. CBCT provides intraprocedural three-dimensional imaging from which structures of interest can be extracted and overlaid on fluoroscopy: this augmented fluoroscopy provides a real-time three-dimensional roadmap guidance that has been shown to increase endobronchial biopsies' diagnostic yield when used with ENB $(17,18)$. In spite of lack of direct visualization, de Ruiter et al. recently showed that augmented fluoroscopy allows the operator to accurately navigate steerable sheaths through the airways and perform biopsies without the use of a bronchoscope $(19,20)$. Contrary to electromagnetic navigation and intermittent cone-beam CT, this real-time fluoroscopy offers the possibility to target moving lesions and/or nodules located outside the airways that would not be directly visualized on bronchoscopy. CBCT can also accurately assess probe positioning with respect to the targeted nodule $(11,21)$ as well as the ablation zone shape and dimensions and monitor treatment effect (22). Additionally, given their smaller outer diameter compared to bronchoscopes, steerable sheaths might offer increased maneuverability in certain specific presentations, and have been shown to offer increased accuracy compared to precurved guiding sheaths $(19,20)$. However, successful MWA of lesions located beyond the airways using this novel approachi.e., steerable sheaths and augmented fluoroscopy without bronchoscopy—has not been previously evaluated.

In this study, it was hypothesized that navigation under CBCT-based augmented fluoroscopy guidance using a steerable sheath and other common interventional radiologic techniques and supplies allows transbronchial MWA of extra-bronchial targets without the use of bronchoscopy. The primary aim was to evaluate feasibility and accuracy of CBCT-based augmented fluoroscopy guided transbronchial MWA in an in vivo swine lung model with tumor mimicking targets. The secondary aim was to describe histological and correlative radiological findings.

We present the following article in accordance with the ARRIVE reporting checklist (available at https://tlcr. amegroups.com/article/view/10.21037/tlcr-21-864/rc).

\section{Methods}

Experiments were performed under an animal study protocol (No. 07-11-018) and approved by the Institutional Animal Care and Use Committee. Animals housings were accredited by the Association for Assessment and Accreditation of Laboratory Animal Care International and in compliance with the United States Department of 
Agriculture Animal Welfare Act and the Guide for the Care and Use of Laboratory Animals.

\section{Procedures and follow-up}

Procedures were performed by three interventional radiologists (M.G., F.R., S.B.S.) with 3-20 years of experience in endovascular and percutaneous procedures. Pigs were in a supine position and under general inhalational anesthesia with isoflurane (1-5\%). To simulate extra-bronchial lung tumors, two synthetic targets were placed for each pig in separate lobes and outside the airways. Targets were equally distributed between upper/middle and lower lobes and between left and right lungs. Each target consisted of a $0.1-0.2 \mathrm{~mL}$ mixture of ethiodized oil: n-butyl cyanoacrylate at $2: 1$ or $3: 1$ ratio added to $0.2-0.3 \mathrm{~g}$ of Tantalum Powder (Trufill, Cordis, Miami Lakes, FL, USA). The solution was percutaneously injected through a 21G-22G needle under CT guidance. A non-contrast CT scan of the chest was repeated after percutaneous injection of lung targets to rule out eventual complications and confirm target positioning outside the airways.

After target placement, the pig was transferred to the angiosuite (Innova 4100, GE Healthcare, Chicago, IL, USA). A middle inspiration breath hold CBCT of the chest was obtained for navigation planning and processed on a dedicated GE workstation: using a semi-automatic extraction tool, the target lesion, the airways to be navigated and the origins of the other bronchi in the ipsilateral lobe were extracted; the operator then determined a desired final position of the steerable sheath in an airway in proximity to the target, landmarked as "parking point". Parking point, target volume, and segmented airways were automatically overlaid on live fluoroscopy (ASSIST software, GE Healthcare, IL, USA) to guide the endobronchial navigation. Augmented fluoroscopy provided a real-time three-dimensional roadmap updated automatically with any change in table position, image intensifier rotation, or magnification. Transbronchial MWA navigation planning and guidance steps are illustrated in Figure 1. The interested reader can find imaging acquisition parameters detailed in Appendix 1.

Endobronchial access was obtained through a $3.5-\mathrm{mm}$ laparoscopic trocar or a 5-mm ENDOPATH XCEL Bladeless Trocar $^{\circledR}$ (Ethicon, Johnson \& Johnson, USA) placed in a T-connector connected to the endotracheal tube. The laparoscopic trocar provided the seal at the endotracheal tube to avoid any air leakage around the steerable sheath. Endobronchial navigation was performed under augmented fluoroscopy only, without bronchoscopy. The primary approach involved navigating through airways to the intended parking point using only a $6.5 \mathrm{Fr}$ steerable sheath (65 or $90 \mathrm{~cm}$ length; Destino Twist, Oscor Inc., FL, USA) (Figure 1C,1D). When this approach was unsuccessful, a 4-Fr or 5-Fr vascular catheter with or without 0.035 " guidewire was used to navigate the steerable sheath to parking point (secondary approach).

Once at parking point, the catheter's steerable tip was used to aim for the target under augmented fluoroscopy. While the steerable sheath's tip remained in the parking position, the flexible probe was introduced through the steerable sheath's lumen. Once outside the steerable sheath, the probe was advanced through the bronchial wall towards the target under augmented fluoroscopy. Indeed, the MWA probe has a sharp tip that allows to penetrate the wall of the airway and travel across the pulmonary parenchyma. When the probe positioning was deemed optimal based on augmented fluoroscopy, a breath hold confirmatory CBCT was performed (Figure 1E). If the probe position was incorrect, the probe was repositioned at the operator's discretion under augmented fluoroscopy, and the confirmatory CBCT was repeated. Navigation to technically challenging locations requiring a sharp curve of the sheath is illustrated in Figure 2A,2B.

Two types of flexible MWA probes (FLEX4 and FLEX 6, NEUWAVE, Ethicon, Johnson \& Johnson) were provided by the manufacturer for the study. The interested reader can find FLEX probe and system presentation, including photos and technical details in Appendix 1. Regardless of target size and location, each target was only ablated once at a power of $100 \mathrm{~W}$ for 5 minutes. After the end of MWA, a CBCT was acquired at 10-15 minutes to assess for target coverage by the ablation zone and eventual complications (Figure 2C,2D). The sheath and probe were then removed from the pig's airways, and the operator navigated and ablated the second target following the same procedural steps. A non-contrast and a contrast enhanced CT scan of the chest were obtained immediately after (Figure $1 F$ ), at $24 \mathrm{~h}$, each following week, and before euthanasia.

Clinical parameters including animal's appetite, cough, and temperature were monitored daily. Pigs were euthanized at the following time points: immediately, 24-48 h, 7-8 days, 13-15 days, and 19 days after MWA, and pathology analysis of the lungs was performed, including measurement of ablation margins (Figures 3,4) and examinations of airways, 

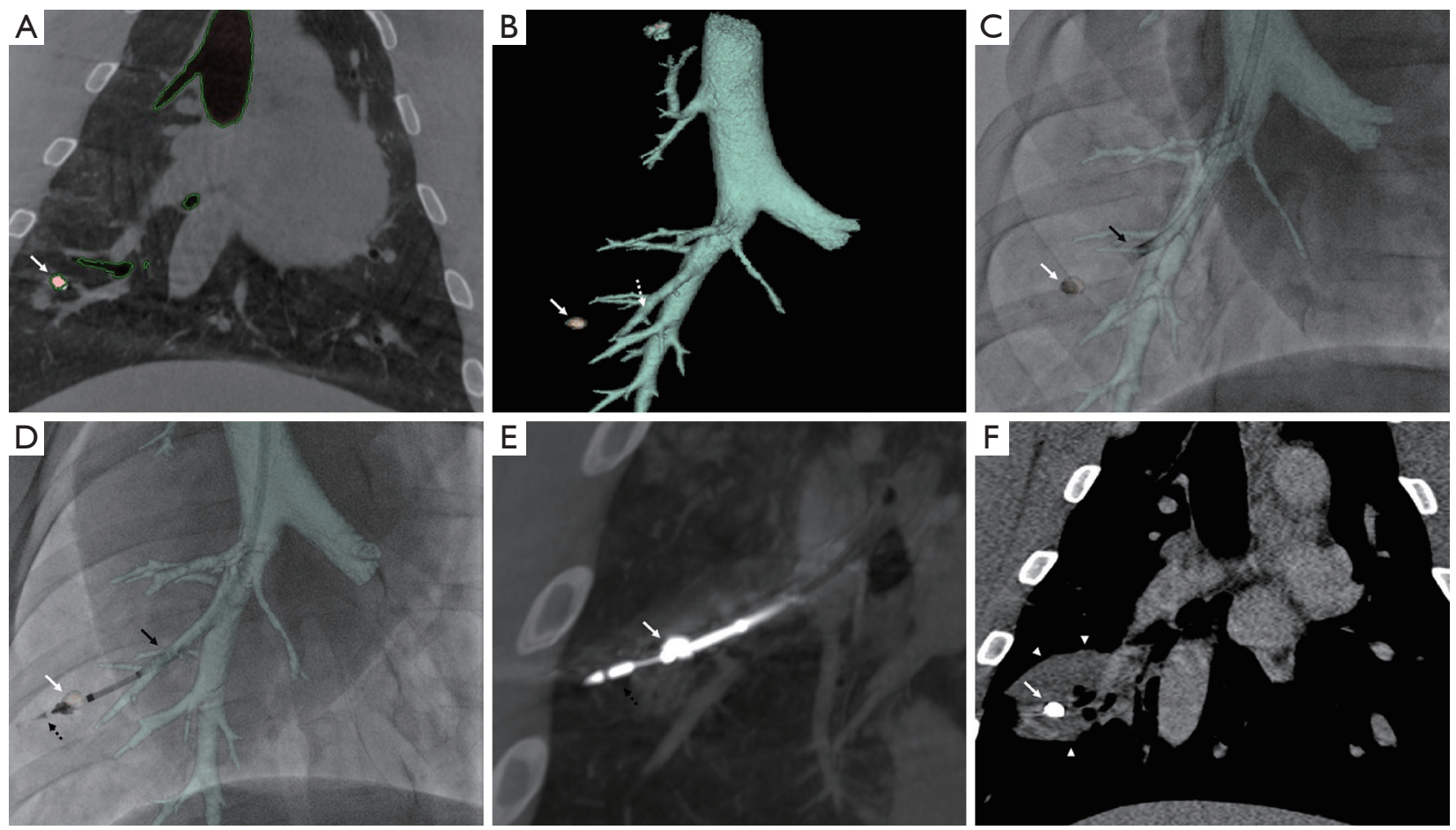

Figure 1 Transbronchial microwave ablation under cone-beam computed tomography based augmented fluoroscopy guidance. Using semi-automatic segmentation on a dedicated GE workstation, the target (white arrow), the targeted airway and the origins of the other bronchi in the ipsilateral lobe were segmented on CBCT (A). The operator determined the desired final position of the sheath in an airway at proximity of the target (white arrow), landmarked as "parking point" (dotted white arrow, B). Extracted structures, here displayed in volume rendering mode (B), were automatically overlaid on live fluoroscopy (ASSIST software, GE Healthcare, IL, USA) to guide the endobronchial navigation (C,D). First step of navigation consisted of parking the steerable sheath's tip (black arrow) at the parking point (C). Once the steerable sheath's tip was aimed towards the target, the flexible MWA probe (dotted black arrow, D) was inserted and advanced transbronchially in the target (white arrow), while the sheath remained in the airway (D). CBCT was repeated to confirm the probe's position in the target (white arrow) before ablation (E). The procedure was successful, with the ablation zone (white arrowheads) covering all the target (white arrow) with $\geq 2 \mathrm{~mm}$ ablation margins, as shown on post-procedural CT coronal section (F). CBCT, cone-beam computed tomography; CT, computed tomography; MWA, microwave ablation.

as detailed in Appendix 1. The aim of the euthanasia at different survival time points was to evaluate the histological modifications of the ablation zone and surrounding lung parenchyma over time.

\section{Study endpoints}

Feasibility was defined as the ability to navigate using only augmented fluoroscopy without a bronchoscope and perform a transbronchial MWA following predefined MWA parameters (100 W-5 minutes). Navigation accuracy was measured on final confirmatory CBCT performed before MWA as the shortest distance in millimeters between the probe and the center of the target. Similarly, the distance between the steerable sheath's tip, when at parking position, and the target's center was measured to evaluate the travel distance of the probe outside the sheath and airways through the lung parenchyma. Navigation times were measured as the time interval in minutes between the introduction of the steerable sheath through the endotracheal tube until: (I) reaching the parking point and (II) correct positioning of the probe in the target on final confirmatory CBCT. The number of confirmatory CBCTs performed (excluding initial CBCT used for navigation planning) was recorded. Complications were reported according to the SIR grading system (23).

Ablation zone was defined as the non-enhancing region or the ground glass opacity with a dense rim (24), and was 

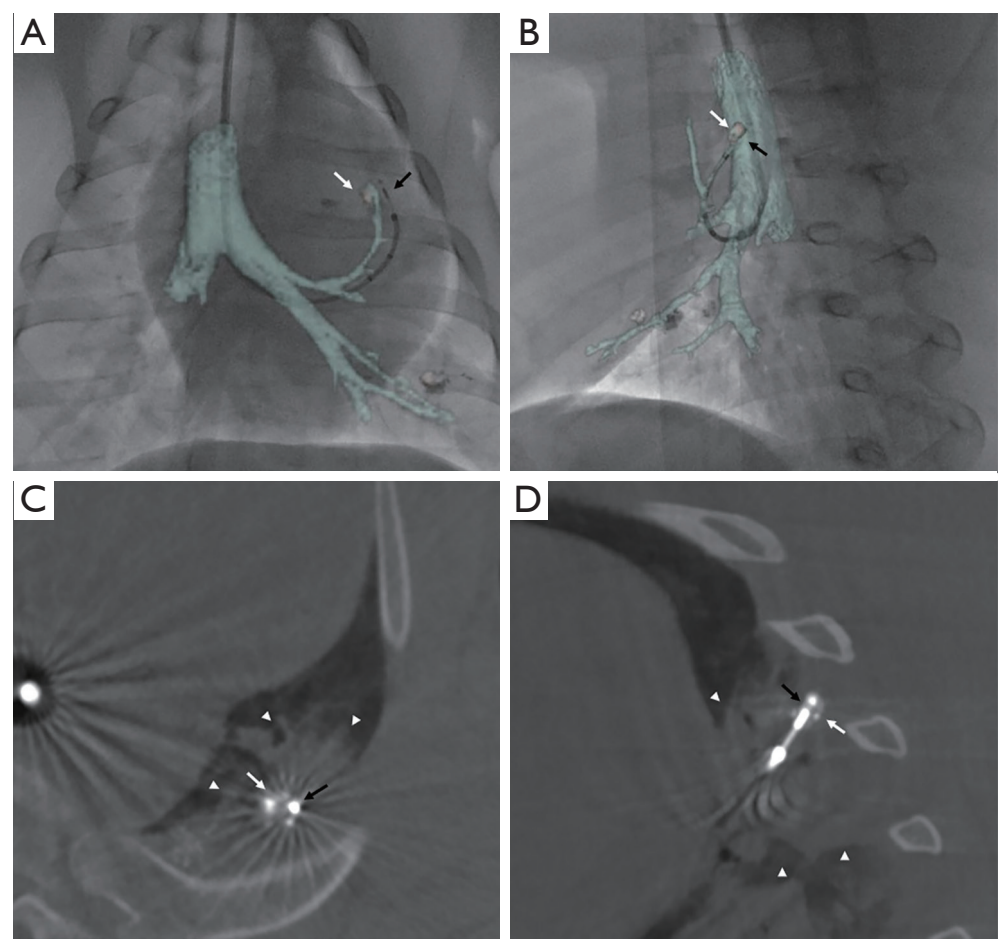

Figure 2 Example of a technically challenging location in left upper lobe. In cases where a sharp curve of the steerable sheath was required, typically for upper lobe targets (white arrow) as shown in this example on real time augmented fluoroscopy images (A,B), the probe was preloaded in the steerable sheath before navigation. Once the parking point was reached, the probe tip was pulled back $1-3 \mathrm{~cm}$ upstream of the sheath end to avoid compromising the flexibility of the sheath's tip. The steerable sheath's tip was then used to aim for the center of the target as previously described, and the MWA flexible probe (black arrow) was advanced. Once this sharp curve was crossed, the sheath's tip partially lost its flexibility. In this case, the MWA probe was successfully placed in the target, with a final $5 \mathrm{~mm}$ distance from the target center. Post-ablation CBCT (axial in C and sagittal in D) showed complete coverage of the target by the ablation zone (white arrowheads). Note the slight distortion of the bronchial anatomy induced by the introduction of the steerable sheath and the probe (A). CBCT, conebeam computed tomography; MWA, microwave ablation.

measured on post-procedural CT multiplanar reformatted images (25) created from non- and post-contrast acquisitions: longest axis diameter (LAD) parallel to the probe's insertion direction, and two orthogonal shortest axis diameters (SAD1 and SAD2). Cavitation on imaging was defined as an airfilled cavity in the ablated parenchyma, excluding the probe's tract (26). The same ablation zone measurements were performed on gross section images. Since ablation time, power adjustments, and/or a second ablation were not allowed, ablation margins were not study endpoints.

\section{Statistical analysis}

Continuous and categorical variables were described as medians [interquartile ranges (IQR)] and raw numbers (proportions, percentages), respectively. Navigation approach (primary $v s$. secondary) and cavitation on pathology were compared using Fisher's test. Navigation distances, navigation times, number of confirmatory CBCTs, and ablation zone dimensions on pathology were compared between lobes using Mann-Whitney test. Ablation zone dimensions at imaging time points were compared using Friedman test, and Wilcoxon signed-rank tests with a Bonferroni correction was used for post hoc analysis. Statistical analysis was performed with SPSS (IBM Corp. Released 2019. IBM SPSS Statistics for Windows, Version 26.0). A P value $<0.05$ was considered statistically significant.

\section{Results}

\section{Pigs and targets characteristics}

Nine Yorkshire pigs were included in this study. Eighteen 

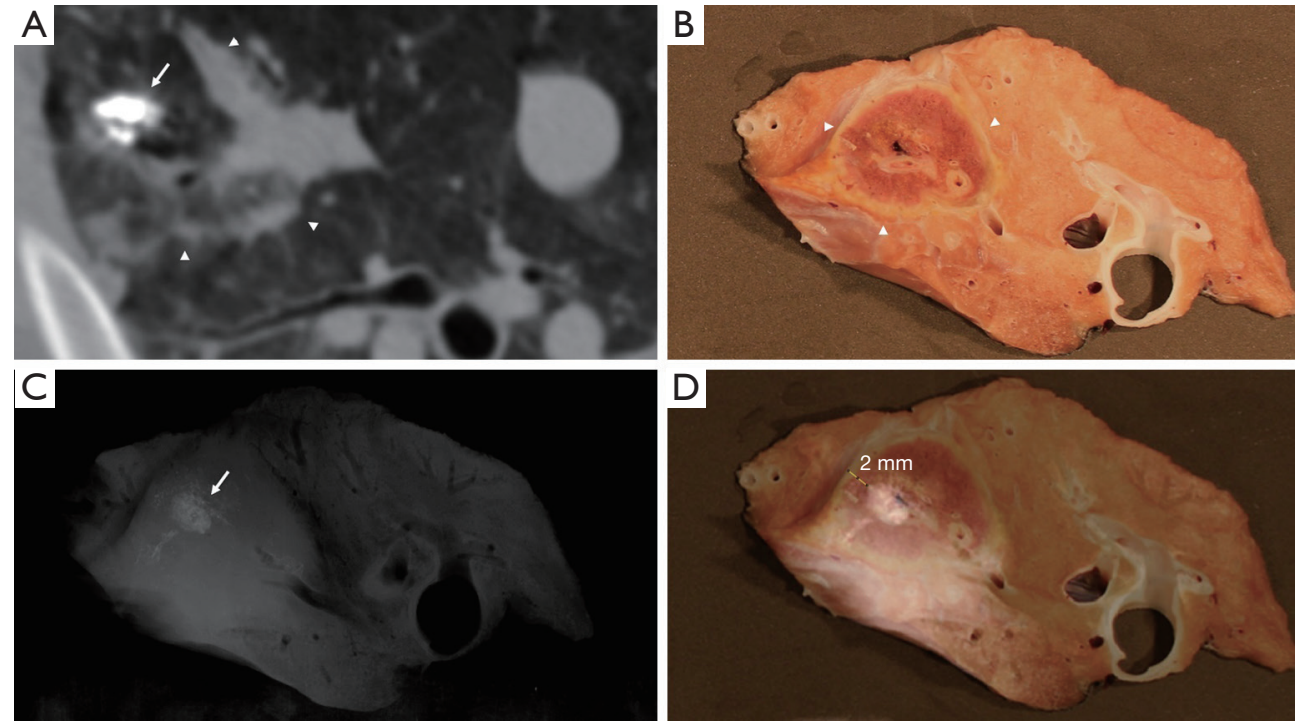

Figure 3 Ablation zone imaging and correlation with histology. Post-ablation CT showing the ablation zone as a ground glass opacity with a peripheral dense rim (white arrowheads) entirely covering the target (white arrow) (A). On the correspondent gross section image, a welldemarcated area of discoloration (coagulation necrosis) surrounded by a fibrotic rim (white arrowheads) is seen (B). Slices were imaged using Faxitron MX20 Specimen Radiography System to confirm target presence in the ablated area (C). Gross image (B) and corresponding radiography $(\mathrm{C})$ were merged and rescaled (D), which allowed to measure minimal and maximal margins using image J software. Here, the minimal ablation margin is illustrated, measured at $2 \mathrm{~mm}(\mathrm{D})$. CT, computed tomography.
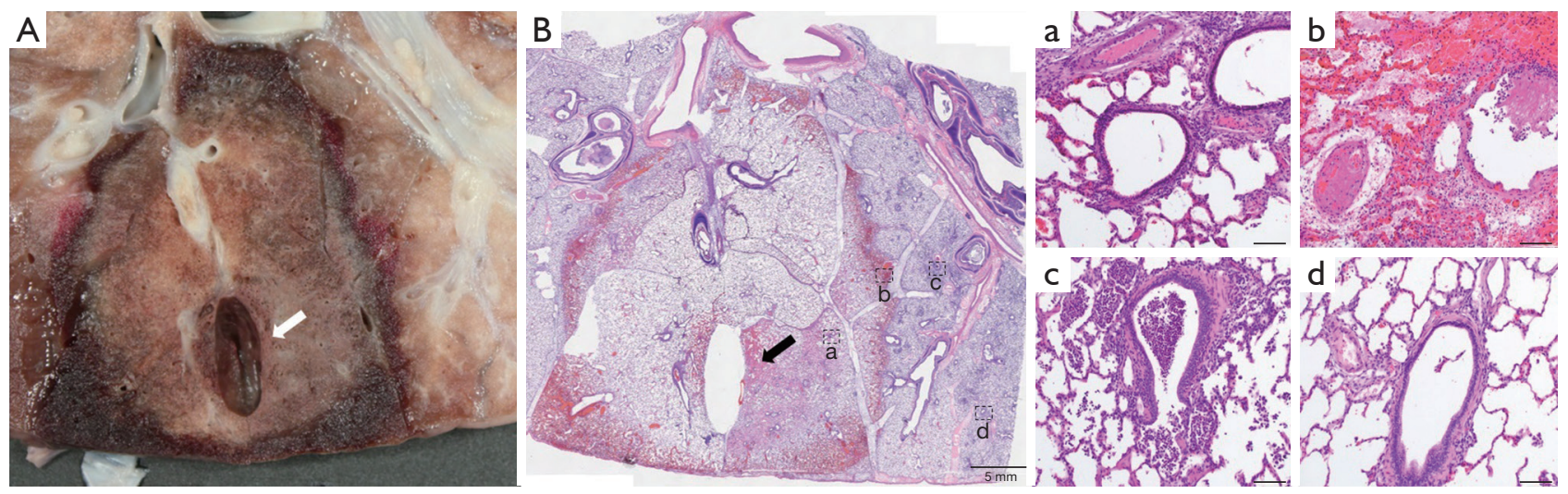

Figure 4 Macroscopic and histological evaluation of ablation zone. Example of an upper lobe ablation zone examined $24 \mathrm{~h}$ after ablation. On macroscopic examination, an ablation zone was immediately apparent as a well-demarcated area of discoloration, with a global ovoid form and a longest diameter parallel to the probe's tip axis (A). On the corresponding histology section stained with hematoxylin and eosin (B, scale bar $=5 \mathrm{~mm}$ ), three zones were noted from the center to the periphery: coagulation necrosis of all structures (alveoli, airways, and blood vessels) with thermal change (hyalinization of tissues) (a), coagulation necrosis of all structures (alveoli, airways, and blood vessels) with vascular thrombosis, hemorrhage, and edema (b) and viable tissue with acute interstitial inflammation (neutrophils, macrophages, edema) and inflammatory exudate in airways (fibrin, neutrophils) (c). Peripheral lung tissue was normal (d). Note an air-filled cavity seen on both gross image (white arrow in A) and corresponding histology (black arrow in B). Photomicrographs' scale bar $=100 \mu \mathrm{m}$ (a-d). 
Table 1 Pigs (total =9) and targets (total =18) characteristics

\begin{tabular}{|c|c|}
\hline Variables & Median [IQR] or numbers [\%] \\
\hline \multicolumn{2}{|l|}{ Sex } \\
\hline Female & $6[67]$ \\
\hline Male & $3[33]$ \\
\hline Age (months) & $3.5[3.3-4.0]$ \\
\hline Weight (kg) & $44[41-45]$ \\
\hline \multicolumn{2}{|l|}{ Post ablation survival } \\
\hline 0 Day & $1[11]$ \\
\hline 1 Day & $2[22]$ \\
\hline 7-8 Days & $2[22]$ \\
\hline 13-19 Days & $4[45]$ \\
\hline \multicolumn{2}{|l|}{ Target dimensions (mm) } \\
\hline Largest diameter & $9[7-11]$ \\
\hline Smallest diameter & $6[4-7]$ \\
\hline \multicolumn{2}{|l|}{ Target side } \\
\hline Right & $11[61]$ \\
\hline Left & 7 [39] \\
\hline \multicolumn{2}{|l|}{ Target lobe } \\
\hline Upper & 7 [39] \\
\hline Middle & $2[11]$ \\
\hline Lower & $9[50]$ \\
\hline \multicolumn{2}{|l|}{ Target segment } \\
\hline Apical & $5[28]$ \\
\hline Anterior & $6[33]$ \\
\hline Medial & $1[6]$ \\
\hline Lateral & $6[33]$ \\
\hline CT bronchus sign ${ }^{\dagger}$ & $0[0]$ \\
\hline \multicolumn{2}{|l|}{ Target zone } \\
\hline Peripheral third of lung & $8[44]$ \\
\hline Middle third of lung & $10[56]$ \\
\hline $\begin{array}{l}\text { Target distance from visceral } \\
\text { pleura or chest wall }(\mathrm{mm})\end{array}$ & 12 [6-20] \\
\hline
\end{tabular}

${ }^{\dagger}$, targets were placed percutaneously outside the airways. CT, computed tomography; IQR, interquartile range. synthetic targets with a median largest diameter of $9 \mathrm{~mm}$ (IQR, 7-11 mm) were ablated. Ten $(10 / 18,56 \%)$ targets were in the middle third of the lung, and $8(8 / 18,44 \%)$ were located at the peripheral third. No CT bronchus sign was observed. Complications after transthoracic percutaneous target placement occurred in $4(4 / 9,44 \%)$ pigs: $2(2 / 9$, $22 \%)$ small, asymptomatic and stable pneumothoraxes not requiring chest tube placement, $1(1 / 9,11 \%)$ minimal asymptomatic intra-alveolar hemorrhage that resolved without intervention (grade: mild), and 1 (1/9, 11\%) complete and symptomatic pneumothorax that required an 8.5-Fr pigtail catheter placement (grade: moderate). The pneumothorax was completely drained before starting the procedure, which did not affect the endobronchial navigation. The chest drain was removed the second day. It is worth mentioning that these complications occurred following target placement in lungs and were not due to the transbronchial MWA procedure. Targets characteristics are detailed in Table 1.

\section{Feasibility, navigation accuracy and time}

Transbronchial MWA using augmented fluoroscopy guidance and without a bronchoscope was feasible in all target locations. Median needle to target distance was $2 \mathrm{~mm}$ (0-4 mm). Accuracy was higher for lower/middle than for upper lobes [0 $\mathrm{mm}$ (IQR, 0-4 mm) vs. $4 \mathrm{~mm}$ (IQR, 3-8 mm), $\mathrm{P}=0.04]$. The primary approach using only a steerable sheath allowed adequate navigation in $11(11 / 18,61 \%)$ targets, and was more frequently used for middle/lower lobes. Median navigation time to reach the parking point and the target were, respectively, 6.5 minutes (IQR, 3.3-22 minutes) and 27 minutes (IQR, 13-40 minutes). Navigation times were shorter for middle/lower lobes. Similarly, navigation time to target decreased with experience, with a median of 36 minutes (IQR, 20-73 minutes) for the first three pigs $v s$. 24 minutes (IQR, 12-39 minutes, $\mathrm{P}=0.3$ ) for the following pigs. Probe positioning was correct the first time in most cases $(10 / 18,56 \%)$, with only one confirmatory CBCT required. The MWA probe was repositioned only once, which required a second confirmatory CBCT, in 5 cases $(5 / 18,28 \%)$. Navigation outcomes and comparisons are detailed in Table 2. 
Table 2 Navigation outcomes

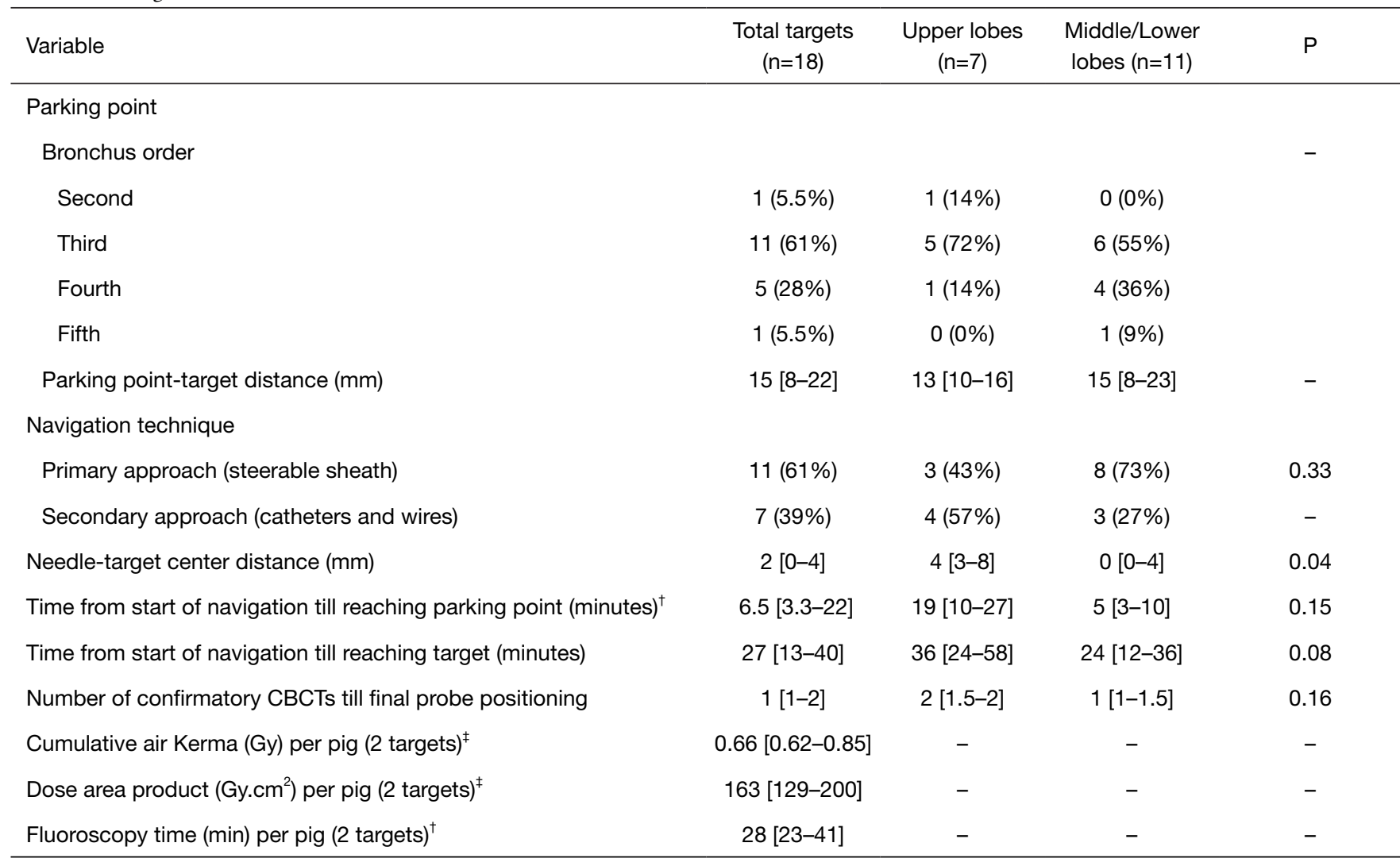

Continuous variables are presented as medians [interquartile ranges] and categorical variables are presented as raw numbers (percentages). ${ }^{\dagger}$, median navigation time to reach the parking point was not statistically significantly different between second and third order vs. fourth and fifth order bronchi, measured respectively at 9 minutes (IQR, 4.5-23.5 minutes) and 6 minutes (IQR, 3-11 minutes) (P=0.2). ${ }^{\ddagger}$, cumulative Air Kerma, dose area product and fluoroscopy time were measured for each pig (2 targets per pig), with a mean of 0.37 Gy, $81.7 \mathrm{~Gy} . \mathrm{cm}^{2}$ and $15 \mathrm{~min}$ respectively per target. CBCT, cone-beam computed tomography.

\section{MWA outcomes and imaging findings}

On immediate post-procedural CT, the ablation zone consisted of consolidation with hypodense non-enhancing center in 13 ablations (13/18, 72\%), ground glass opacity with a dense rim in 2 ablations $(2 / 18,11 \%)$, and only ground glass opacity in 3 ablations $(3 / 18,17 \%)$. On immediate post-procedural CT, median LAD was $38 \mathrm{~mm}$ (IQR, 30-40 mm). Ablation zone size peaked on day 7-8 then decreased on day 13-19 (Table 3). Cavitation was immediately observed after 10 ablations (10/18, 56\%), and partially decreased in size or remained stable on 1 and 2 weeks follow-up. In 9 ablations $(9 / 18,50 \%)$, there was atelectasis, consolidation, and/or air bronchograms in the parenchyma, downstream from the parking point. No signs of pulmonary infarct were observed.

Complete coverage of the target by the ablation zone was achieved in $17(17 / 18,94 \%)$ targets. In the single case where the target was outside the ablation zone, the target was in the anterior part of the left upper lobe, with a final needle-target distance of $10 \mathrm{~mm}$. The probe exited a large airway $(>5 \mathrm{~mm})$ and was immediately in contact with a large $(>5 \mathrm{~mm})$ pulmonary artery, which may have resulted in heat-sink effects and yielded a small ablation zone of $15 \times 12 \times 10 \mathrm{~mm}^{3}$ on CT. The median maximum temperatures reached during ablation and at the end of the ablation were measured through the flexible probe thermocouple at $88.5^{\circ} \mathrm{C}\left(\mathrm{IQR}, 83-90^{\circ} \mathrm{C}\right)$ and $73.5^{\circ} \mathrm{C}\left(\mathrm{IQR}, 66.3-79.5^{\circ} \mathrm{C}\right)$, respectively.

\section{Safety}

No severe or life-threatening complications occurred during transbronchial MWA, in particular, no pneumothorax or 
Table 3 Evolution of ablation zone dimensions on imaging follow-up.

\begin{tabular}{|c|c|c|c|c|c|c|}
\hline $\begin{array}{l}\text { Ablation zone } \\
\text { dimensions }\end{array}$ & $\begin{array}{l}\text { СВCT } 10-15 \text { minutes } \\
\text { after end of ablation }\end{array}$ & $\begin{array}{c}\text { Same day } \\
\text { post-procedural CT }\end{array}$ & Day 1 CT & Day 7-8 CT & Day $13-19$ CT & $P$ \\
\hline LAD (mm) & 38 [33-42] & 38 [30-40] & 43 [37-48] & 45 [37-51] & 29 [24-41] & $0.02^{*}$ \\
\hline SAD2 (mm) & 23 [19-26] & 26 [20-28] & 27 [21-31] & 28 [22-33] & 21 [20-23] & - \\
\hline
\end{tabular}

Continuous variables are presented as medians [interquartile range]. *, there was a statistically significant difference in ablation zone LAD depending on the day of imaging assessment $(P=0.02)$. Post hoc analysis with Wilcoxon signed-rank tests was conducted with a Bonferroni correction applied, resulting in a significance level set at $P<0.017$. Median LAD increased from post-procedural $C T$ to days $7-8(P=1)$ then decreased from days 7-8 to days 13-19 ( $P=0.012)$. CBCT, cone-beam computed tomography; $C T$, computed tomography; $L A D$, longest axis diameter; SAD, shortest axis diameter.
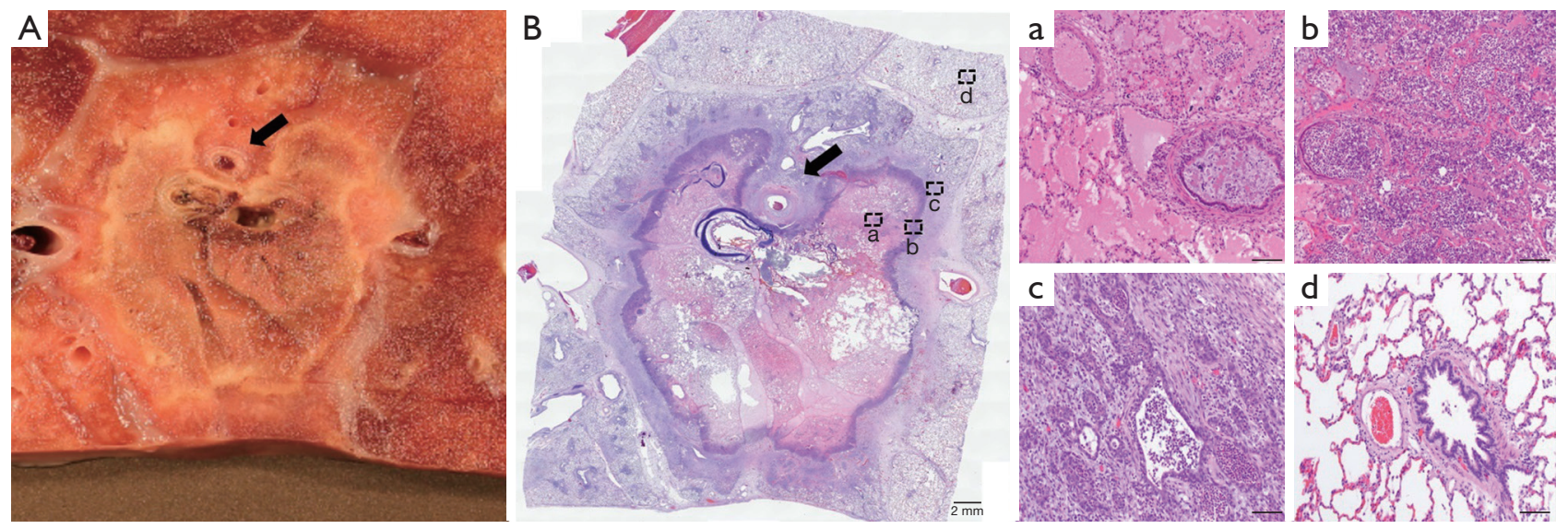

Figure 5 Ablation zone with heat sink effect. Example of heat sink effect (arrow in A and B) in contact with a 3-mm artery, here shown on an examination performed 8 days after ablation, on both macroscopic examination (A) and corresponding histology section stained with hematoxylin and eosin (B, scale bar $=2 \mathrm{~mm}$ ). Three zones were noted from the center to the periphery (B): coagulation necrosis with thermal change (a), coagulation necrosis with marked neutrophilic and histiocytic inflammation, hemorrhage, and edema (b) and viable tissue with fibrosis, epithelial hyperplasia, and neutrophilic inflammation of airways and alveoli (c). Peripheral lung tissue was normal (d). Photomicrographs' scale bar $=100 \mu \mathrm{m}(\mathrm{a}-\mathrm{d})$.

hemorrhage. Post-procedural pain (inappetence) occurred in 1 pig (Pig 8) and was treated medically (buprenorphine $0.005 \mathrm{mg} / \mathrm{kg}$ intravenously and meloxicam $0.4 \mathrm{mg} / \mathrm{kg}$ injectable or oral). Rib fractures were observed in the ablation zone in 2 pigs (Pigs 6 and 7) and were treated medically (grade: moderate). These ablations were in the apical segment of the right upper lobe, which is particularly narrow in pigs, and both ablation zones covered adjacent ribs (27). A slight pleural effusion was observed in 1 pig (Pig 7) the day following MWA and spontaneously resolved on 1-week follow-up (grade: mild). Pig 7 also had inappetence, intermittent cough and leukocytosis on day 9 , but no fever or new consolidation on imaging were observed. Symptoms resolved after 3 days of intramuscular injections of ceftiofur at $4 \mathrm{mg} / \mathrm{kg}$ (grade: moderate).

\section{Pathology}

Eight pigs had histopathologic analysis for a total of 16 ablated targets. The first study pig only underwent postprocedural CT analysis before euthanasia. At macroscopic examination, ablation zones appeared as well-demarcated areas of discoloration with an ovoid form (Figure $3 B$, Figure $4 A$ and Figure $5 A$ ). Heat sink effect in contact with $>3 \mathrm{~mm}$ vessels and $>3 \mathrm{~mm}$ bronchioles occurred in 6 $(6 / 16,38 \%)$ targets. An example of heat sink effect seen on both macroscopic examination and corresponding histology section is shown in Figure 5A,5B. Ablation zone 
dimensions on gross pathology were larger in upper lobes and peripheral targets (Table 4). LAD on gross pathology correlated well with LAD on the CT done the day of euthanasia (Pearson correlation coefficient $=0.80, \mathrm{P}<0.01$ ).

On histology (Figure 4B), ablation zones were composed of three zones in pigs euthanized at $24 \mathrm{~h}$ after ablation, from center to periphery: (I) coagulation necrosis with thermal change, (II) coagulation necrosis with vascular thrombosis, hemorrhage, and edema, and (III) viable tissue with acute interstitial inflammation. In pigs that survived 7-8 days (Figure 5B), inflammation zone displayed fibrosis and epithelial hyperplasia of airways and alveoli. Fibrosis was more apparent in pigs euthanized after 2 weeks. The lung tissue outside the ablation zone was normal. Air-filled cavitation (Figure $4 A, 4 B$ ) in the necrotic zone occurred in $10(10 / 16,63 \%)$ cases. Additional findings and ablation margins are in Table 4.

\section{Discussion}

This is the first study demonstrating feasibility and accuracy of transbronchial MWA under CBCT- augmented fluoroscopy guidance using only a steerable sheath without bronchoscopy. In a swine model with extra-bronchial tumor mimics, the procedure was feasible in all target locations, with a final median distance from the needle to the target center of $2 \mathrm{~mm}$, and no ablation-related pneumothorax or lifethreatening complications. This high accuracy is in line with a previous study on CBCT-augmented fluoroscopy guidance that reported a $4.0-4.9 \mathrm{~mm}$ error for airway navigation with the same sheath but without tumor targets (19). In comparison, Eberhardt et al. reported a mean error of $9 \mathrm{~mm}$ for ENB, and Yarmus et al. reported a median of $4 \mathrm{~mm}$ miss with robotic bronchoscopy, despite larger lesions and higher CT bronchus sign rate $(10,28)$. Accuracy comparison to bronchoscopy is however limited given differences in target locations, with $56 \%$ targets placed in the middle third of the lung in this study. Accuracy reported in our study reflects "real life" performances with this technique, and is in fact related to augmented fluoroscopy guidance errors and to the flexibility/maneuverability of the devices used for probe positioning.

Most endobronchial navigation systems rely on chest CT performed several days before the procedure. Differences in lung anatomy between the preprocedural CT and the day of the procedure can lead to significant mismatch between the real target location and the virtual navigation map ("CT to body divergence"), decreasing navigation accuracy
$(11,12)$. In contrast, CBCT is performed immediately before navigation, in the same position and under the same ventilation and anesthesia parameters. The provided augmented fluoroscopy map is automatically registered to the patient without manual fusion and allows real time assessment of probe positioning relative to the lesion during the procedure. Besides eliminating issues related to "CT to body divergence", real-time fluoroscopy offers the ability to target lesions located away from the airways that would not be visualized on bronchoscopy. As shown in this study, the bronchus was punctured away from the target, and optimal needle positioning under imaging guidance was not dependent on a bronchus leading to the nodule. Another advantage of real-time imaging is the possibility to target moving nodules, without the need for multiple probe positioning and repeat CBCT. Although this approach does not allow mediastinal staging, most of lung thermal ablations are performed on lung metastasis where lymph node staging is not required. Regarding radiation safety, dose area product per target was measured at a mean of $81.7 \mathrm{~Gy} . \mathrm{cm}^{2}$, in concordance with the patient dose reference levels proposed for fluoroscopically guided interventional procedures (29).

Although a slight distortion of the bronchial anatomy compared to the augmented fluoroscopy map was sometimes noticed with probe introduction in some challenging locations (Figure 2A,2B), this was less with the sheath than a bronchoscope. A confirmatory CBCT clarified needle position in the target. This confirmatory CBCT can be used to update the augmented fluoroscopy navigation map once the parking point is reached, although this was not needed in this study (19). Navigation time was compatible with regular clinical settings, with a median time to reaching the target of 27 minutes compared to a mean of 116.2 minutes with transbronchial MWA using ENB (7).

As for flexibility of the devices, the obtained high accuracy provides further evidence supporting the use of steerable sheaths and the ability to maneuver them through distal airways $(19,20)$. However, higher accuracy and lower navigation times were obtained for lower lobes compared to upper lobes. Difficulty negotiating upper lobes after a sharp curve was due to a limited maximum delivery angle of the steerable sheath, which was particularly reduced after insertion of the MWA probe. Indeed, the MWA probe has a straight rigid tip of $1 \mathrm{~cm}$ that made the sharp turns more difficult. This is similar to maximum needle delivery angle loss previously described after insertion of a biopsy needle through the steerable sheath (22), and emphasizes two main 
Table 4 Pathology results

\begin{tabular}{|c|c|c|}
\hline & Numbers [\%] or medians [IQR] & $P$ \\
\hline Total $(n=16)$ & 32 [23-43] & \\
\hline Upper lobes $(n=7)$ & $41[30-51]$ & 0.04 \\
\hline Middle/lower lobes $(n=9)$ & 28 [20-37] & - \\
\hline Peripheral $(n=6)$ & 34 [30-45] & - \\
\hline \multicolumn{3}{|l|}{ Ablation zone SAD1-Gross section (mm) } \\
\hline Total $(n=16)$ & 24 [19-29] & \\
\hline Upper lobes $(n=7)$ & 24 [20-38] & 0.2 \\
\hline Peripheral $(n=6)$ & 25 [20-31] & - \\
\hline \multicolumn{3}{|l|}{ Ablation zone SAD2-Gross section (mm) } \\
\hline Total $(n=16)$ & 22 [19-29] & \\
\hline Upper lobes $(n=7)$ & 27 [20-30] & 0.5 \\
\hline Middle/lower lobes $(n=9)$ & 23 [17-29] & - \\
\hline Central $(n=10)$ & $20[17-24]$ & 0.03 \\
\hline Peripheral $(n=6)$ & 30 [25-33] & - \\
\hline \multicolumn{3}{|l|}{ Ablation margins $(\mathrm{mm})^{\dagger}$} \\
\hline Peripheral $(n=6)$ & $5[83]$ & - \\
\hline Adjacent $(<5 \mathrm{~mm})$ to airways $>3 \mathrm{~mm}$ diameter $(\mathrm{n}=3)$ & $1[33]$ & 0.5 \\
\hline Distant $(>5 \mathrm{~mm})$ from airways $>3 \mathrm{~mm}$ diameter $(n=13)$ & 9 [69] & - \\
\hline \multicolumn{3}{|l|}{ Associated findings ${ }^{\ddagger}$} \\
\hline Fibrinous and neutrophilic pleuritis & $14[88]$ & - \\
\hline Pericardial fibrosis & $1[6]$ & - \\
\hline
\end{tabular}


limitations of this technique. First, the operator's ability to advance the steerable sheath and to steer its tip may be compromised after negotiating the sharp curve required to reach upper lung lobes. Improvements in flexibility of the steerable sheaths may overcome this shortcoming. Second, managing sharp curves with the probe's straight rigid tip of $1 \mathrm{~cm}$ may be challenging. Preloading the probe in the steerable sheath before navigation can be helpful. A less stiff microwave probe would also help facilitate the procedure. Considering these limitations, careful attention must be given to navigation planning.

In comparison to a percutaneous approach, one of the major strengths of transbronchial MWA is that the flexible probe does not transgress the pleura, which resulted in no pneumothorax. Rib fractures within the ablation zone have been previously described following percutaneous ablations performed close to the chest wall (30). These fractures are probably a consequence of bone necrosis induced by high temperature of the MWA (30). Tethering of the rib to the ablation zone resulting in extensive traction on the bone may also be involved (30). Transbronchial access may also facilitate ablation of central tumors in proximity to major airways or major vessels, offering an alternative or complementary approach for nodules difficult to target percutaneously. Regarding hemoptysis, none occurred following transbronchial MWA in our study. Although it is acknowledged that this remains a major concern, and that lack of direct visualization when only using steerable sheaths may be a limitation, it is often asymptomatic in the lungs (31), and life-threatening hemorrhage are very rare (32). If massive hemoptysis occurs after or during ablation, an endobronchial blocker may be placed under fluoroscopic guidance (using the catheter or wire already in place) in order to stabilize the patient before definitive treatment such as arterial embolization (33).

Histology confirmed complete coagulation necrosis, with some cases of susceptibility to heat sink effect (26). Ablation zones were larger in upper lobes and peripheral targets due to regional variations in ventilation and perfusion, again similar to percutaneous ablations (34). However, occlusion of the bronchus by the steerable sheath may induce atelectasis. Putting in communication the lung parenchyma with the airways or ablations proximity to segmental bronchi probably explains the high rate of cavitation observed $(26,35,36)$, although the clinical significance remains uncertain (37). In contrast to transbronchial MWA, percutaneous procedures can be performed under conscious sedation (38).
While the use of CBCT-based augmented fluoroscopy guidance is expected to improve endobronchial navigation accuracy, percutaneous lung biopsy is still associated with higher diagnostic yield compared to endobronchial biopsies (17). This supports the need for prospective randomized clinical trials comparing endobronchial MWA outcomes to the established percutaneous approach that has been associated with high local tumor control rates, in particular for lesions $<2-3 \mathrm{~cm}(39-42)$.

This study has several limitations. First, this was a small animal study and further data are required to evaluate the safety of this technique. Second, thermal ablations were only performed on synthetic targets in a healthy lung. Effect of tumor histology and density on needle penetration and ablation outcomes could not be assessed. Third, differences in airways anatomy between swine and humans might limit generalization of accuracy results (27). Fourth, no randomization of target locations was performed, although care was taken to equally select bilateral targets, in both upper and lower lobes. Fifth, tool-in-catheter deflection was not measured. Finally, a bronchoscopy was not performed after the ablation to assess for endobronchial complications, but this was ruled out by clinical and imaging follow-up and gross examination of the airways.

\section{Conclusions}

In summary, transbronchial MWA under CBCT-based augmented fluoroscopy using a steerable sheath and without bronchoscopy is feasible and accurate. While it offers an interesting alternative that decreases the risk of pneumothorax, comparison to the established percutaneous approach is needed to determine optimal patient selection parameters. Central tumors located near large airways, tumors with a CT bronchus sign or patients who would not tolerate a pneumothorax may be potential targets.

\section{Acknowledgments}

The authors thank Govind Srimathveeravalli who provided valuable advice regarding the lungs' fixation technique; we thank Christopher Cheleuitte-Nieves, Margaret Reilly, Joann Phifer, Yuliana Miranda, Stephanie Harris-Ash, and Brian Cuevas who helped with animal experiments; we thank Jacqueline Candelier who helped with necropsy.

Funding: This work was supported by Johnson \& Johnson. This research was funded in part through the NIH/NCI 
Cancer Center Support Grant P30 CA008748.

\section{Footnote}

Reporting Checklist: The authors have completed the ARRIVE reporting checklist. Available at https://tlcr. amegroups.com/article/view/10.21037/tlcr-21-864/rc

Data Sharing Statement: Available at https://tlcr.amegroups. com/article/view/10.21037/tlcr-21-864/dss

Conflicts of Interest: All authors have completed the ICMJE uniform disclosure form (available at https://tlcr.amegroups. com/article/view/10.21037/tlcr-21-864/coif). MG is a grant recipient for a postdoctoral research fellowship from GE Healthcare. RD is a GE Healthcare employee. LM is a full-time employee of NeuWave Medical. KR is a fulltime employee of NeuWave Medical. EZ has research grants from SIR, RSNA, NANETS, MSK, AACR, Ethicon, Novartis. ALT has research grants funding from Boston Scientific and Johnson and Johnson; receives consulting fees from Boston Scientific, AstraZeneca, Johnson and Johnson, and Endocare. RDS is a consultant and speaker for NeuWave Medical and Varian; a consultant for Ethicon; a speaker for Boston Scientific. SBS is a shareholder and grant recipient from Johnson \& Johnson; a consultant for Olympus, Microbot, Varian, Xact Robotics, Aperture Medical and Advantagene; has grants from GE Healthcare, AngioDynamics and Elesta. The other authors have no conflicts of interest to declare.

Ethical Statement: The authors are accountable for all aspects of the work in ensuring that questions related to the accuracy or integrity of any part of the work are appropriately investigated and resolved. Experiments were performed under an animal study protocol (No. 07-11018) and approved by the Institutional Animal Care and Use Committee. Animals housings were accredited by the Association for Assessment and Accreditation of Laboratory Animal Care International and in compliance with the United States Department of Agriculture Animal Welfare Act and the Guide for the Care and Use of Laboratory Animals.

Open Access Statement: This is an Open Access article distributed in accordance with the Creative Commons Attribution-NonCommercial-NoDerivs 4.0 International License (CC BY-NC-ND 4.0), which permits the non- commercial replication and distribution of the article with the strict proviso that no changes or edits are made and the original work is properly cited (including links to both the formal publication through the relevant DOI and the license). See: https://creativecommons.org/licenses/by-nc-nd/4.0/.

\section{References}

1. Ferguson J, Egressy K, Schefelker R, et al. Bronchoscopically-Guided Microwave Ablation in the Lung. Chest 2013;144:87A.

2. Zheng A, Wang X, Yang X, et al. Major complications after lung microwave ablation: a single-center experience on 204 sessions. Ann Thorac Surg 2014;98:243-8.

3. Yuan HB, Wang XY, Sun JY, et al. Flexible bronchoscopyguided microwave ablation in peripheral porcine lung: a new minimally-invasive ablation. Transl Lung Cancer Res 2019;8:787-96.

4. Sebek J, Kramer S, Rocha R, et al. Bronchoscopically delivered microwave ablation in an in vivo porcine lung model. ERJ Open Res 2020;6:e00146-2020.

5. Lau K, Spiers A, Pritchett M, et al. Bronchoscopic ImageGuided Microwave Ablation of Peripheral Lung Tumours - Early Results. J Thorac Oncol 2018;13:S542.

6. Pritchett M, Reisenauer J, Kern R, et al. Image-Guided Transbronchial Microwave Ablation of Peripheral Primary Lung Tumors with a Flexible Probe: First in Us Experience. Chest 2020;158:1452a-3a.

7. Chan JWY, Lau RWH, Ngai JCL, et al. Transbronchial microwave ablation of lung nodules with electromagnetic navigation bronchoscopy guidance-a novel technique and initial experience with 30 cases. Transl Lung Cancer Res 2021;10:1608-22.

8. Kashiwabara K, Fujii S, Tsumura S, et al. Efficacy and safety of transbronchial microwave ablation therapy under moderate sedation in malignant central airway obstruction patients with respiratory failure: a singleinstitution retrospective study. J Cancer Res Clin Oncol 2021;147:2751-7.

9. Khandhar SJ, Bowling MR, Flandes J, et al. Electromagnetic navigation bronchoscopy to access lung lesions in 1,000 subjects: first results of the prospective, multicenter NAVIGATE study. BMC Pulm Med 2017;17:59.

10. Yarmus L, Akulian J, Wahidi M, et al. A Prospective Randomized Comparative Study of Three Guided Bronchoscopic Approaches for Investigating Pulmonary Nodules: The PRECISION-1 Study. Chest 
2020;157:694-701.

11. Pritchett MA. Prospective Analysis of a Novel Endobronchial Augmented Fluoroscopic Navigation System for Diagnosis of Peripheral Pulmonary Lesions. J Bronchology Interv Pulmonol 2021;28:107-15.

12. Pritchett MA, Bhadra K, Calcutt M, et al. Virtual or reality: divergence between preprocedural computed tomography scans and lung anatomy during guided bronchoscopy. J Thorac Dis 2020;12:1595-611. Erratum in: J Thorac Dis 2020;12:4593-5.

13. Sabath BF, Casal RF. Bronchoscopic ablation of peripheral lung tumors. J Thorac Dis 2019;11:2628-38.

14. Venturini M, Cariati M, Marra P, et al. CIRSE Standards of Practice on Thermal Ablation of Primary and Secondary Lung Tumours. Cardiovasc Intervent Radiol 2020;43:667-83.

15. Casal RF, Sarkiss M, Jones AK, et al. Cone beam computed tomography-guided thin/ultrathin bronchoscopy for diagnosis of peripheral lung nodules: a prospective pilot study. J Thorac Dis 2018;10:6950-9.

16. Setser R, Chintalapani G, Bhadra K, et al. Cone beam CT imaging for bronchoscopy: a technical review. J Thorac Dis 2020;12:7416-28.

17. Pritchett MA, Schampaert S, de Groot JAH, et al. ConeBeam CT With Augmented Fluoroscopy Combined With Electromagnetic Navigation Bronchoscopy for Biopsy of Pulmonary Nodules. J Bronchology Interv Pulmonol 2018;25:274-82.

18. Verhoeven RLJ, Fütterer JJ, Hoefsloot W, et al. Cone-Beam CT Image Guidance With and Without Electromagnetic Navigation Bronchoscopy for Biopsy of Peripheral Pulmonary Lesions. J Bronchology Interv Pulmonol 2021;28:60-9.

19. de Ruiter QMB, Karanian JW, Bakhutashvili I, et al. Endobronchial Navigation Guided by Cone-Beam CTBased Augmented Fluoroscopy without a Bronchoscope: Feasibility Study in Phantom and Swine. J Vasc Interv Radiol 2020;31:2122-31.

20. de Ruiter QMB, Fontana JR, Pritchard WF, et al. Endovascular steerable and endobronchial precurved guiding sheaths for transbronchial needle delivery under augmented fluoroscopy and cone beam CT image guidance. Transl Lung Cancer Res 2021;10:3627-44.

21. Hohenforst-Schmidt W, Zarogoulidis P, Vogl T, et al. Cone Beam Computertomography (CBCT) in Interventional Chest Medicine - High Feasibility for Endobronchial Realtime Navigation. J Cancer 2014;5:231-41.

22. Meram E, Longhurst C, Brace CL, et al. Comparison of
Conventional and Cone-Beam CT for Monitoring and Assessing Pulmonary Microwave Ablation in a Porcine Model. J Vasc Interv Radiol 2018;29:1447-54.

23. Khalilzadeh O, Baerlocher MO, Shyn PB, et al. Proposal of a New Adverse Event Classification by the Society of Interventional Radiology Standards of Practice Committee. J Vasc Interv Radiol 2017;28:1432-1437.e3.

24. Abtin FG, Eradat J, Gutierrez AJ, et al. Radiofrequency ablation of lung tumors: imaging features of the postablation zone. Radiographics 2012;32:947-69.

25. Suh RD, Wallace AB, Sheehan RE, et al. Unresectable pulmonary malignancies: CT-guided percutaneous radiofrequency ablation--preliminary results. Radiology 2003;229:821-9.

26. Kodama H, Ueshima E, Gao S, et al. High power microwave ablation of normal swine lung: impact of duration of energy delivery on adverse event and heat sink effects. Int J Hyperthermia 2018;34:1186-93.

27. Judge EP, Hughes JM, Egan JJ, et al. Anatomy and bronchoscopy of the porcine lung. A model for translational respiratory medicine. Am J Respir Cell Mol Biol 2014;51:334-43.

28. Eberhardt R, Anantham D, Herth F, et al. Electromagnetic navigation diagnostic bronchoscopy in peripheral lung lesions. Chest 2007;131:1800-5.

29. Vano E, Sanchez R, Fernandez JM, et al. Patient dose reference levels for interventional radiology: a national approach. Cardiovasc Intervent Radiol 2009;32:19-24.

30. Alexander ES, Hankins CA, Machan JT, et al. Rib fractures after percutaneous radiofrequency and microwave ablation of lung tumors: incidence and relevance. Radiology 2013;266:971-8.

31. Smith SL, Jennings PE. Lung radiofrequency and microwave ablation: a review of indications, techniques and post-procedural imaging appearances. Br J Radiol 2015;88:20140598.

32. Kashima M, Yamakado K, Takaki H, et al. Complications after 1000 lung radiofrequency ablation sessions in 420 patients: a single center's experiences. AJR Am J Roentgenol 2011;197:W576-80.

33. Nicholas Zerona, Priyesh Patel, Ihab Haddadin. Fluoroscopy-Guided Placement of Endobronchial Blockers: A Case Series. Innovations in Surgery and Interventional Medicine 2021;1:15-9.

34. Al-Hakim RA, Abtin FG, Genshaft SJ, et al. Defining New Metrics in Microwave Ablation of Pulmonary Tumors: Ablation Work and Ablation Resistance Score. J Vasc Interv Radiol 2016;27:1380-6. 
35. Wolf FJ, Grand DJ, Machan JT, et al. Microwave ablation of lung malignancies: effectiveness, CT findings, and safety in 50 patients. Radiology 2008;247:871-9.

36. Bojarski JD, Dupuy DE, Mayo-Smith WW. CT imaging findings of pulmonary neoplasms after treatment with radiofrequency ablation: results in 32 tumors. AJR Am J Roentgenol 2005;185:466-71.

37. Okuma T, Matsuoka T, Yamamoto A, et al. Factors contributing to cavitation after CT-guided percutaneous radiofrequency ablation for lung tumors. J Vasc Interv Radiol 2007;18:399-404.

38. Hoffmann RT, Jakobs TF, Lubienski A, et al. Percutaneous radiofrequency ablation of pulmonary tumors--is there a difference between treatment under general anaesthesia and under conscious sedation? Eur J Radiol 2006;59:168-74.

39. Vogl TJ, Naguib NN, Gruber-Rouh T, et al. Microwave ablation therapy: clinical utility in treatment of pulmonary metastases. Radiology 2011;261:643-51.

40. Healey TT, March BT, Baird G, et al. Microwave Ablation for Lung Neoplasms: A Retrospective Analysis of LongTerm Results. J Vasc Interv Radiol 2017;28:206-11.

41. Nelson DB, Tam AL, Mitchell KG, et al. Local Recurrence After Microwave Ablation of Lung Malignancies: A Systematic Review. Ann Thorac Surg 2019;107:1876-83.

42. Iezzi R, Cioni R, Basile D, et al. Standardizing percutaneous Microwave Ablation in the treatment of Lung Tumors: a prospective multicenter trial (MALT study). Eur Radiol 2021;31:2173-82.
Cite this article as: Ghosn M, Elsakka AS, Ridouani F, Doustaly R, Mingione L, Royalty K, Ziv E, Alexander E, Maxwell A, Monette S, Kim HS, Short RF, Tam AL, Suh RD, Solomon SB. Augmented fluoroscopy guided transbronchial pulmonary microwave ablation using a steerable sheath. Transl Lung Cancer Res 2022;11(2):150-164. doi: 10.21037/tlcr-21864 


\section{Appendix 1 Methods}

\section{Imaging acquisition parameters}

Cone beam computed tomography images were acquired with a $40 \mathrm{~cm} \times 40 \mathrm{~cm}$ flat-panel detector angiosuite (Innova 4100, GE Healthcare, IL, USA); 244 projections were obtained through a $200^{\circ}$ rotation at $10^{\circ} \%$ (for planning and ablation zone assessment) and $20 \% \mathrm{~s}$ (for probe position confirmation). Computed tomography images were all acquired in supine position with breath hold (LightSpeed RT16, GE Healthcare, IL). Acquisition parameters were: tube voltage, $120 \mathrm{kV}$; tube current, $440 \mathrm{~mA}$; slice thickness, $0.625 \mathrm{~mm}$; pitch, 1.375:1; matrix, 520×520. Contrast enhanced images were obtained 35-45 s, $90 \mathrm{~s}$, and $180 \mathrm{~s}$ after intravenous injection of $80-100 \mathrm{~mL}$ of Iohexol (Omnipaque 300, GE Healthcare, Milwaukee) at a $2.5 \mathrm{~mL} / \mathrm{s}$ rate (25).

\section{NEUWAVE FLEX microwave ablation system description}

The NEUWAVE FLEX System is a fully featured soft tissue ablation system that uses small diameter flexible ablation probes, a single microwave source with a $100 \mathrm{~W}$ microwave power amplifier operating at $2.45 \mathrm{GHz}$, a $\mathrm{CO}_{2}$ based cooling system, and a Power Distribution Module (PDM). Microwave energy is applied to the target tissue, heating the tissue to the point of necrosis.

One, easy to use, touch-screen user interface controls the system. Microwave energy is delivered through one distinct channel to the ablation probe. The $\mathrm{CO}_{2}$ cooling system helps limit the temperature of the probe cable. The PDM is designed to have a highly efficient large cable from the PDM to the power amplifier, which allows for more energy delivery to the ablation probe.

Two flexible ablation probe types are available for use with the NEUWAVE FLEX System: the FLEX4 and the FLEX6. The probe types have different tips to aid in tissue access. The model number indicates the sharpness of the tip: the higher the number, the sharper the tip. FLEX probe models are French gauge 6 (outer diameter of less than $2 \mathrm{~mm}$ ). Each ablation probe contains temperature measurement sensors that help monitor performance and ensure patient and operator safety.

The NEUWAVE FLEX System has several safety features which monitor system performance. The system will automatically stop delivering energy to the patient in response to system performance issues.

\section{Pathology analysis}

Pigs were euthanized with an intravenous injection of pentobarbital sodium $(87 \mathrm{mg} / \mathrm{kg})$ and phenytoin sodium $(11 \mathrm{mg} / \mathrm{kg})$ at the following survival timepoints: immediately, 24-48 h, 7-8 days, 13-15 days, and 19 days after microwave ablation. Following euthanasia, the lungs and trachea were removed en bloc. The lungs were filled through an endotracheal tube with $10 \%$ neutral buffered formalin at a pressure of $20 \mathrm{~cm}$ of water and were distended to their approximate in vivo inspiratory volume (26). They were immersed in formalin for $48-72 \mathrm{~h}$ then entirely sectioned at $5-7 \mathrm{~mm}$ intervals in the axial plane. Photographs of gross sections with a measurement reference were obtained. All slices with a visible ablation zone were processed in alcohol and xylene, embedded in paraffin, sectioned at 5 micro thickness, stained with hematoxylin and eosin and were reviewed by a board-certified veterinary pathologist. Since the target material could not be visualized on gross or histologic examination following the first pig's examination, gross slices from the subsequent pigs that had a visible ablation zone on gross analysis were radiographed using a digital Faxitron MX20 Specimen Radiography System (Qados, Cross Technologies plc, Berkshire, UK). Radiographies of gross slices were rescaled and overlaid on corresponding gross slices photos, and minimal and maximal ablation margins were measured on the merged photos using image J software (43).

\section{References}

43. Schneider CA, Rasband WS, Eliceiri KW. NIH Image to ImageJ: 25 years of image analysis. Nat Methods 2012;9:671-5. 

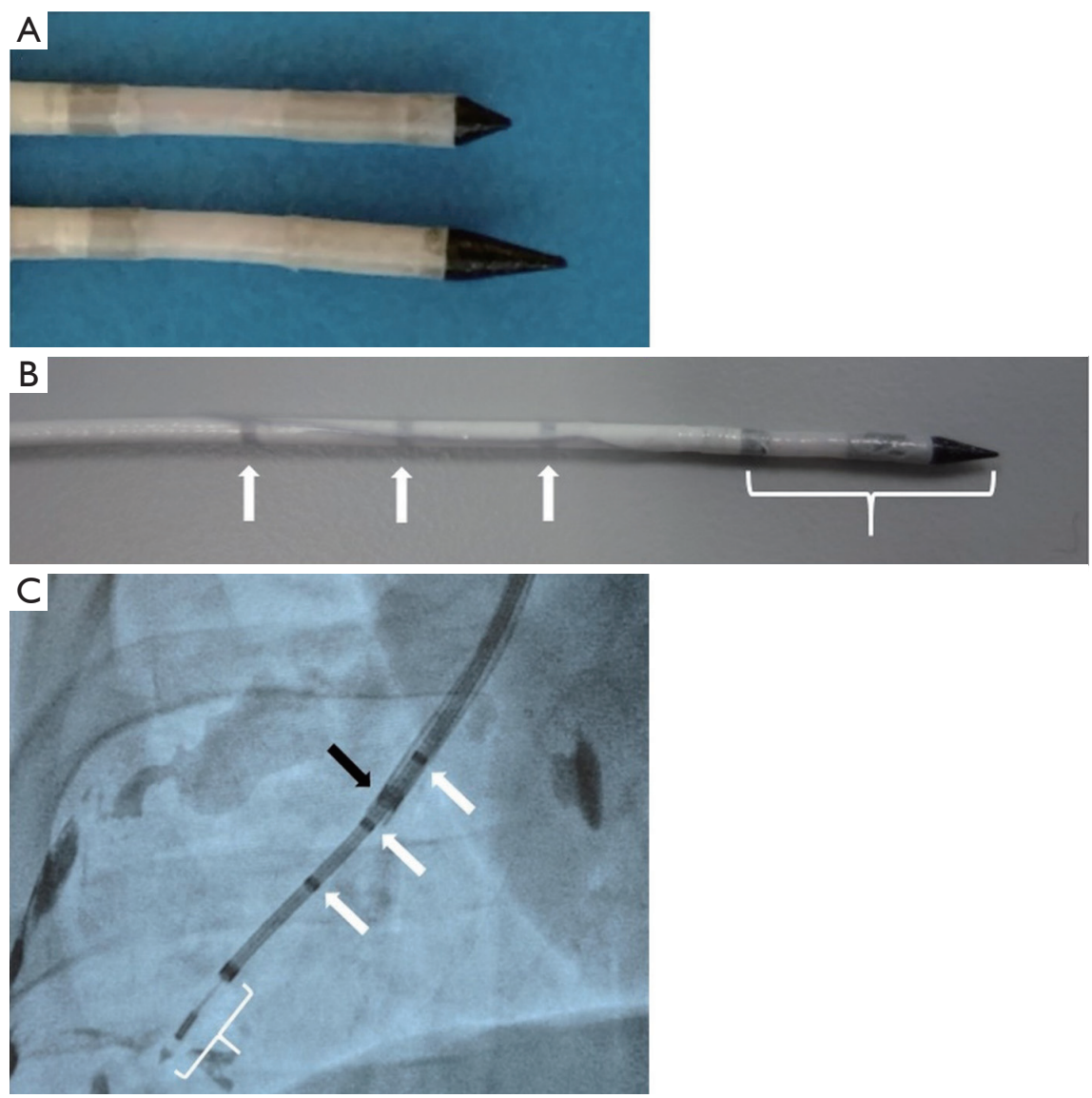

Figure S1 FLEX probe and system presentation (photos and technical details). Images of the FLEX ablation probe showing the conical tip geometries (A) of the FLEX4 (top, A) and FLEX6 (bottom, A) and some key probe features (B) including antenna section (white brace) and distal end marker bands (white arrows) at 3, 4, and $5 \mathrm{~cm}$ from the tip. These features are visible in two-dimensional X-ray imaging (C) of the FLEX Probe (white arrows) as seen deployed through the steerable sheath (Destino Twist, Oscor Inc., FL, USA) (black arrow). 